\title{
An improved seismicity picture of the Southern Tyrrhenian area by the use of OBS and land-based networks: the TYDE experiment
}

\author{
Tiziana Sgroi $\left({ }^{1}\right)$, Thomas Braun $\left({ }^{2}\right)$, Torsten Dahm $\left({ }^{3}\right)$ and Francesco Frugoni $\left({ }^{1}\right)$ \\ (') Istituto Nazionale di Geofisica e Vulcanologia, Roma, Italy \\ ${ }^{(2)}$ Istituto Nazionale di Geofisica e Vulcanologia, Sede di Arezzo, Italy \\ ${ }^{(3)}$ Institut für Geophysik, Universität Hamburg, Hamburg, Germany
}

\begin{abstract}
The problem of large location uncertainties for seismicity occurring in the Southern Tyrrhenian Sea have been partially overcame during the implementation of the long-term scientific mission of the TYrrhenian Deep-sea Experiment (TYDE), which allowed the installation of 14 wide-band Ocean Bottom Seismometers (OBS) and Hydrophones (OBH) in the period December 2000-May 2001 on the seafloor around the Aeolian and Ustica Islands. Local events recorded at land-stations have also been observed on the seismograms of the Ocean Bottom Seismic Network (OBSN). Moreover, some hundreds of low magnitude events, undetected from the land networks, have been recorded. We combined the readings of body wave arrival times from OBS-OBH with those from land-stations to locate seismic events. We focused our study on three clusters of events representative of the seismic activity of the area: i) «deep» events, ii) Ustica, iii) NE-Sicily. The analysis of the integrated data set of the seismicity off-shore and on-shore, obtained from the combined land-OBS seismic network (Ustica sequence and Deep events), has improved locations in terms of RMS residuals, azimuthal gap, epicentral and hypocentral errors. Moreover, further classes of events have been analysed: the first includes some local events that could be located only by integrating single trigger readings from the few available land-stations with the OBSN-data; the second comprises local events that have been detected only by the OBS-OBH stations. In particular, the last cluster underlines the importance of an OBSN in the Tyrrhenian deep basin to reveal its unknown intense micro-seismicity, permitting to better understand both the tectonic and geodynamic picture of the area.
\end{abstract}

Key words ocean bottom seismometer-integrated seismic networks - Southern Tyrrhenian Sea - Aeolian Islands

\section{Introduction}

Ocean Bottom Seismometer Networks (OB$\mathrm{SN}$ ) are used in different regions of the world to

Mailing address: Dr. Tiziana Sgroi, Istituto Nazionale di Geofisica e Vulcanologia, Via di Vigna Murata 605, 00143 Roma, Italy; e-mail: sgroi@ingv.it improve the locations of earthquakes occurring off-shore and in coastal areas and to complete data sets from the land-based networks. In the Northern Japan Trench hundreds of seismic events, recorded between July-August 1992, have been relocated by Hino et al. (1996) using both OBS and land network data, improving focal depth errors to less than $5 \mathrm{~km}$. Lawton et al. (1982) studied the seismicity in the area of the Kodiak continental shelf (Alaska) and reported a mean dislocation of about $12 \mathrm{~km}$ of the hypocenters by integrating the OBS readings in their land network data set. Earthquake relocations, recorded in the Central Juan de Fuca plate (west coast of 
North America) by a joint land and OBS network, provided a more accurate evaluation of the seismicity of the intraplate region (Bebel et al., 1992). Also the use of OBSN allowed other aspects of seismological research to be developed, as an example in tomographic studies performed in the coastal region of Northern Chile, improving both the hypocenter locations and three-dimensional $v_{p}$ and $v_{p} / v_{s}$ structure (Husen et al., 2000).

The precise location of off-shore seismicity performed by land-based seismic stations is often difficult. Especially in the case of an insular or peninsular seismic network, the observations of local earthquakes occurring in coastal areas show large azimuthal gaps, resulting in a large location error. In Italy this problem particularly concerns the Southern Tyrrhenian Basin, one of the most interesting regions of the Mediterranean Sea considering its intense geodynamic activity linked to tectonic and volcanic processes. Up to now only two short-term OBSs experiments have been performed in the Southern Tyrrhenian Sea: in 1987, a small OBS network operated for 11 days close to the Calabrian coast, recording microseismicity not detected by permanent and temporary landbased seismic networks (Soloviev, 1990); in 1996, a three week passive seismic campaign was realised by a joint Italian-Japanese collaboration around the Aeolian Islands and Ustica Island (Aoyagi et al., 1997). The attempt to integrate seismic data from land-based and OBS-stations and to improve the epicentre determinations revealed the following problems:

i) The use of short-period seismometers $(4.5 \mathrm{~Hz})$, mainly used for seismic reflection surveys, turned out to be not appropriate for studies of local seismicity in the area.

ii) The three week long experiment took place in a seismic quiescent period.

iii) The spacing of the OBSN (about $40 \mathrm{~km}$ ) proved to be too large for the low magnitude local seismicity location, therefore only a few seismic events were simultaneously detected by more than 2 OBS-stations (Beranzoli et al., 1999).

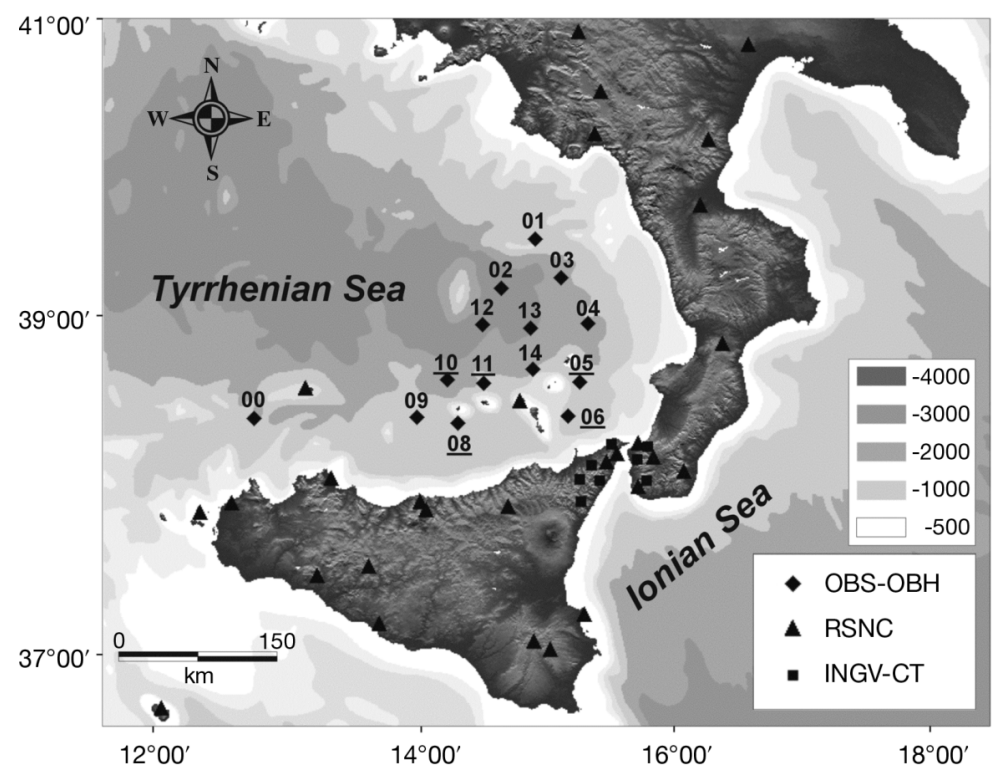

Fig. 1. Location of OBS-OBH (diamonds) and land-based seismic stations (triangles and squares) used in the present work. Each ocean bottom station was equipped with an OBH (1 channel), those equipped with an additional 3-component seismic sensor (OBS) are represented by underlined numbers. Station no. 07 is not reported on the map as it was not recovered. The label 00 reports the position of the GEOSTAR multi-parametric observatory, hosting an $\mathrm{OBH}$. 
The implementation of the long-term scientific mission of the multi-parameter Ocean Bottom Observatory GEOSTAR (Beranzoli et al., 2000) in a depth around 1900 m near Ustica Island (station 00 in fig. 1) was a good opportunity to plan a new OBS experiment.

Between December 2000 and May 2001 the Institute of Geophysics of the University of Hamburg (IGH), the Research Centre for Marine Science at Kiel (GEOMAR) and the GEOSTARgroup of the Istituto Nazionale di Geofisica e Vulcanologia (INGV) carried out a joint seismological experiment in the Southern Tyrrhenian Sea, the so called TYyrrhenian Deep-sea Experiment (TYDE). A 14 stations OBSN was installed on the seafloor around the Aeolian Islands in the area comprised between latitude $38.4^{\circ} \mathrm{N}-39.6^{\circ} \mathrm{N}$ and longitude $14.0^{\circ} \mathrm{N}-15.4^{\circ} \mathrm{N}$ (stations $01-14$ in fig. 1), at water depths ranging between $1500 \mathrm{~m}$ and $3500 \mathrm{~m}$. Each station consisted of a wideband hydrophone $(\mathrm{OBH})$, six of them were additionally equipped with a 3-component seismic broadband sensor (OBS) (Dahm et al., 2002). All the stations except OB07 were recovered. Additionally, some temporary broad-band seismic stations were installed in Sicily and on the Aeolian and Ustica Islands, to increase the density of the permanent seismic network configuration (Braun et al., 2001). The data set collected during the TYDE-experiment overcomes the difficulties encountered in the past experiments, because: i) we used broad-band instrumentation, able to record both local seismicity and even teleseismic events; ii) the entire experiment lasted 6 months; iii) OBSN was well-spaced (about $30 \mathrm{~km}$ ) allowing the simultaneous detection of local seismic events at 3 or more OBSN-stations.

The present paper analyses the hypocentral determinations of the local seismicity as determined by the land-based network and the OB$\mathrm{SN}$. We discuss the difficulties concerning the choice of the crustal velocity model, demonstrating that the integration of observations from land-based stations and from the OBSN is useful to locate earthquakes in the Tyrrhenian Basin more accurately. In particular, the integration processes contribute to improve the hypocenter determinations, resulting in less scattered locations associated both to reduced depth and epicentral errors and lower values of azimuthal gap and RMS. Moreover, we show how only the presence of the OBSN placed in the Southern Tyrrhenian Basin allows an intense micro-seismicity linked to both volcanic and tectonic processes to be recorded.

\section{Structural setting of the Southern Tyrrhenian Sea}

In addition to high quality seismic data recorded by a suitable network configuration, the accuracy of epicentre locations depends on the reliability of the available crustal velocity model. In the past decades the main structural characteristics of the crust under the Southern Tyrrhenian Sea have been the subject of numerous studies, using mainly data from seismic refraction experiments. To extrapolate velocity models also for depths or areas outside the studied crustal sections, we briefly review the main results of those former studies on the structural setting of the Southern Tyrrhenian area.

The tectonic evolution of the Tyrrhenian Basin must be considered in a more general geodynamic process of the collision between European and African plates (Dewey, 1989). This collision caused the subduction of the ancient tethyan lithosphere under the European plate, with the fragmentation of the European plate margin and the Alpine orogenic belt and the opening of the Tyrrhenian Basin (e.g., Malinverno and Ryan, 1986; Faccenna et al., 1997; Argnani, 2000), which started in the Miocene (Kastens and Mascle, 1990).

The Southern Tyrrhenian Basin is characterised by the presence of two areas floored by oceanic crust: the Vavilov Basin of Pliocene age and the Marsili Basin, where opening started less then 2 Ma ago (Marani and Trua, 2002). The Marsili Basin is surrounded to the south and to the east by the Aeolian Arc, constituted by volcanic islands and submerged volcanoes of Quaternary age (Barberi et al., 1974). Partly, these volcanoes rest on a crystalline basement of Alpine origin which outcrops extensively on the Calabro-Peloritan sector of the Apenninic thrust belt.

A clear deep seismicity is present under the Marsili Basin (Anderson and Jackson, 1987; Gi- 
ardini and Velonà, 1991; Selvaggi and Chiarabba, 1995), with hypocentral distribution that depicts a very narrow, continuous slab dipping about $70^{\circ}$ to the NW down to a depth of about $500 \mathrm{~km}$. Tomographic images suggest a connection between the subducted slab and the Ionian lithosphere (Piromallo and Morelli, 1997; Cimini, 1999).

Seismic catalogues (INGV, 2003) report crustal seismicity in the study area both along the coastal areas and in the submerged sector of the Apenninic thrust belt and in correspondence to the Aeolian Islands. Off-shore Sicily Island, this seismicity has been related by Neri et al. (1996) to two main faults systems crossing the Aeolian Islands archipelago (Sisifo and Vulcano), evidenced by geological studies (Frazzetta et al., 1982; Ghisetti and Vezzani, 1982) and DDS surveys (Finetti and Del Ben, 1986). Crustal seismic events in the Calabrian sector can be related to an extensional tectonic regime.

\section{Experimental setup}

For the data analysis described in this paper we created a joint database collecting data recorded by the following seismic networks:

$O B S N$ - The 14 stations of the Ocean Bottom Seismometer Network (OBSN; fig. 1) were equipped with wide-band sensors: all the stations included a hydrophone, and six stations were also equipped with a 3-component geophone (fig.
2); the 20 bit digitiser recorded seismic data at a sampling rate of $50 \mathrm{~Hz}$. Further details about technical aspects of the entire instrumentation pool can be found in Dahm et al. (2002). Moreover, we used data recorded from the hydrophone mounted on the multi-parameter Ocean Bottom Observatory GEOSTAR, deployed near Ustica Island (Gasparoni et al., 2002).

$R S N C$ - The INGV operates the National Centralised Seismic Network (RSNC), with more than 100 short-period seismometric stations, mostly vertical-component, installed on the Italian territory. In this study, we use data recorded by about 25 stations, located in areas surrounding the Southern Tyrrhenian Sea (fig. 1). These stations are equipped with a S-13 Teledyne Geotech sensor, acquiring continuous data with a sampling rate of $50 \mathrm{~Hz}$.

$I N G V-C T$ - In Eastern Sicily operates a local seismic network managed by the INGV section of Catania (INGV-CT), consisting of more than 50 short-period stations. They constitute a local network mainly employed in the seismic monitoring of Mount Etna volcanic edifice, while the seismic stations placed in the Messina Strait and Iblean area permit to locate tectonic earthquakes occurring near the coastal area. In the present study, we used data from eight (fig. 1) 3-component stations (Mark L4C), installed in a restricted area surrounding the Messina Strait, with a $160 \mathrm{~Hz}$ sampling rate.

The time signal for the RSNC and INGV-CT data is set by GPS for all the stations, while the

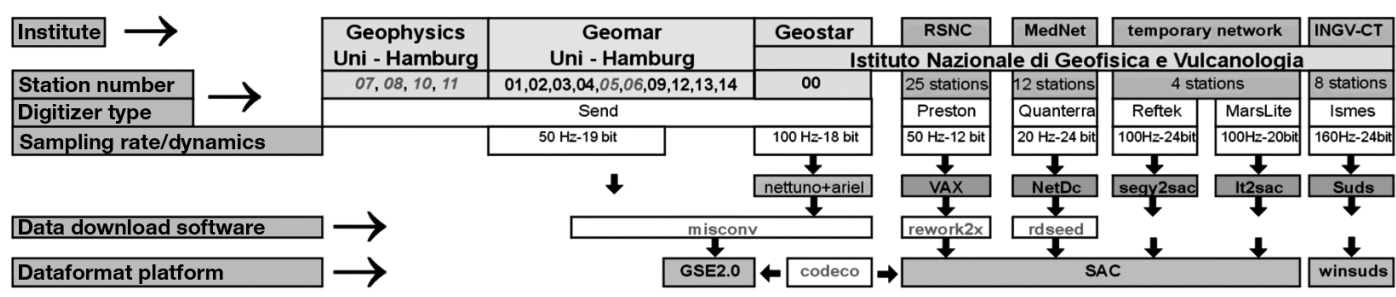

Fig. 2. Organisation of seismic data acquired and used in the framework of the TYDE experiment. GEOMAR, Uni-Hamburg, and GEOSTAR are in charge of the OBS/OBH instruments used during the experiment. Istituto Nazionale di Geofisica e Vulcanologia is responsible for the on land networks: for this study we did not use the MedNet and temporary networks data set. An OBH was mounted on all the off-shore stations; the number of the station is typed in italic style when an OBS sensor was mounted, too. In the figure, the characteristics of seismic sensors and the procedures to unify the data format are shown. 
timing for the OBSN cannot take advantage of satellite signals when they operate on the seafloor. Each OBS has an internal clock which was synchronised with the GPS clock signal before the deployment $\left(t_{\text {start }}\right)$ and just after its recovery $\left(t_{\text {end }}\right)$. The time delays $\left(t_{\text {end }}-t_{\text {start }}\right)$ observed at each single station did not exceed $\pm 0.6 \mathrm{~s}$ during the 6months campaign. Being the drift of the OBS clock signal linear, the correction for this time delay was realised before the data processing.

Figure 2 sketches the instrumental characteristic, the seismic data processing, and data format conversion.

\section{Preparatory activities for the event locations}

The earthquake locations based on data from combined land and OBS networks meet several problems not usually encountered by a land network. In the present chapter, we briefly describe all the preparatory work and the problems concerning the integration of different data sets:

i) the choice of the location routine;

ii) the definition of selection criteria for the local events to be integrated;

iii) the choice of velocity models.

\subsection{Choice of the earthquake location program}

Currently, the hypocenters reported in the bulletins of RSNC and INGV-CT are determined by location routines based on Hypo71 (Lee and Lahr, 1972). In order to integrate seismic data recorded at stations deployed on continental crust (RSNC and INGV-CT) and oceanic crust (OBSN), the earthquake location program has to comply with negative station altitudes and with strong crustal inhomogeneities.

After balancing carefully the advantages and limits of the different available programs, we decided to use a relatively new location routine, HYPOSAT (Schweitzer, 2001). HYPOSAT accepts negative station altitudes, but its main feature of interest for our application is the possibility to use at once different velocity models for the location procedure.
Preliminary tests with a small cluster of sample events, demonstrated the adequacy of HYPOSAT compared to other location routines. While the determined epicentres were generally well constrained, the focal depths for most events could be determined with minor uncertainties by introducing local velocity models.

\subsection{Data selection}

The choice of the local seismic events suitable for the relocation analysis was based on the INGV bulletins (RSNC and INGV-CT). The catalogue data were divided into (a) located earthquakes (\$5) and (b) non-located seismic events, where only single station triggers were reported $(\S 6)$.

In the first category (a), the waveforms recorded by seismic land-stations were checked in order to verify the arrival times, the uniformity of the readings, and their relative weights. The final data set consisted of about 800 earthquakes in a magnitude range $1.5<M<3.5$, which occurred between December 1st, 2000 and May 18th, 2001.

In order to concentrate the present study on the analysis of seismicity in the Southern Tyrrhenian Sea, we made the choice to exclude, $a$ priori, from the analysis earthquakes reported in the INGV-bulletins located in the area of Mt. Etna, Ionian Sea, Calabria and inner Sicily. Among the located earthquakes, we selected those where recordings showed a good signal-to-noise-ratio, attributed them to three geographical clusters and used these data for the subsequent integrations with the OBSN recordings:

Cluster 1 - A few deep seismic events in the Southern Tyrrhenian Sea, with reported focal depths below $100 \mathrm{~km}$ (13 events).

Cluster 2 - A small seismic sequence near Ustica Island (14 events).

Cluster 3 - A seismic swarm in the area of Mts. Nebrodi-Peloritani system (Northern Sicily) (20 events).

In the second category (b), we included the single stations triggers from RSNC, to be integrated with the OBS readings through the event association process. Moreover, this category comprehends OBS readings relative to events recorded only by the OBS array. 


\subsection{Choice of the crustal velocity model}

The complex geodynamic evolution of the Southern Tyrrhenian Basin is confirmed by a pronounced heterogeneity of the crust and of the surrounding emerged regions. The depth of the Moho ranges from $10 \mathrm{~km}$ in the oceanic-type Marsili and Vavilov basins (Recq et al., 1984; Duschenes et al., 1986; Kastens and Mascle, 1990) to more than $35 \mathrm{~km}$ under the Apenninic Belt in Calabria and Sicily, where the crust has continental characteristics. Moreover, the upper crust presents lateral changes in lithology and in thickness of structural units (AA.VV., 1991).

To approximate such pronounced structural variations and taking into account $1 \mathrm{D}$ velocity models proposed in literature, we divided the Southern Tyrrhenian area into 9 sub-zones, each

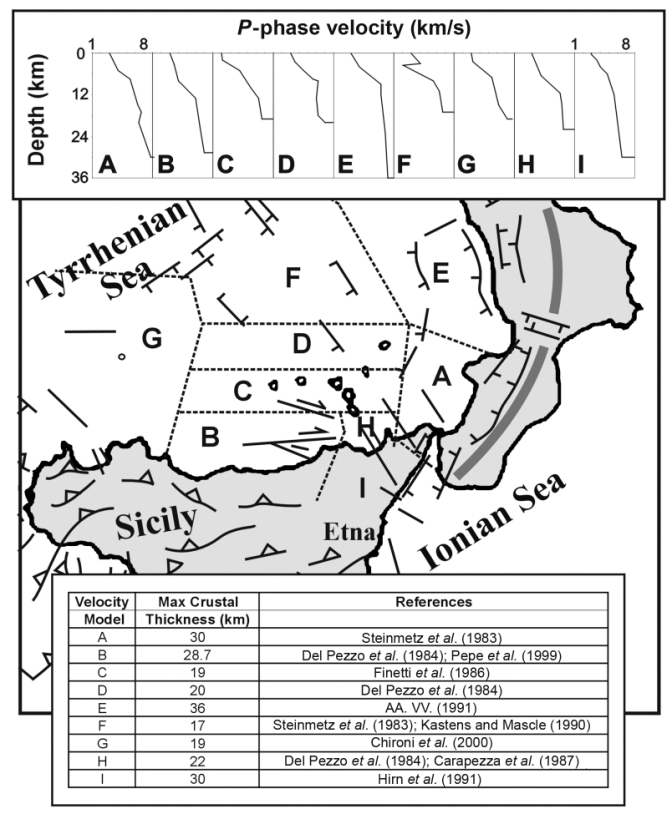

Fig. 3. Subdivision of the Southern Tyrrhenian Sea in 9 sub-zones (structural map of south Italy modified from Meletti et al., 2000), each of them characterised by a different velocity model. On the upper part the pattern of $P$-phase velocity versus the depth for the different models is shown. On the bottom, the table representing the maximum crustal thickness of each velocity model with the relative references is reported. one parameterised by an individual crustal velocity model to be used for location. Figure 3 shows the 9 sub-zones and the corresponding $P$ phase velocity $1 \mathrm{D}$ models selected from literature. For each zone we also reported the maximum crustal thickness and the main reference used for the definition of the velocity models. For the upper mantle we used the velocity model ak135 (Kennett et al., 1995).

We started the location procedure using the model of the area where each event has been originally located according to the bulletin. If large errors were associated to the hypocentral parameters, we repeated the location substituting the 1D velocity model with that one of the neighbouring zone, until the result was satisfactory.

\section{Land-based and integrated earthquake locations}

Forty-seven seismic events have been relocated by integrating land-based stations with the OBSN. Each earthquake, belonging to one of the three different clusters (1-3), was located following two steps: i) locations based exclusively on the readings of land stations; ii) integration extended to the combined land-OBSN observations. All the integrations are characterised by RMS residuals smaller than $0.60 \mathrm{~s}$, seismogram records of at least four $P$-phases and one $S$-phase, and a station coverage in at least two azimuthal quadrants.

Figures 4-6 represent the relocations for events of clusters 1-3. Grey filled circles depict epi-/hypocenters determined by using time readings of the land based seismic network; black filled circles represent the relocations after integration of the OBSN-observations; the dislocations between the old and the new locations are indicated by connecting lines. Table I summarises for each cluster the numerical results of the hypocentral determinations, the location errors and the respective relative dislocations.

Generally the solutions of the relocations are much better constraint in terms of location error, RMS and azimuthal gap. This is due to the combination of two effects. On one hand the integration of the OBSN data increases the number of observations (phases) and reduces the azimuthal 

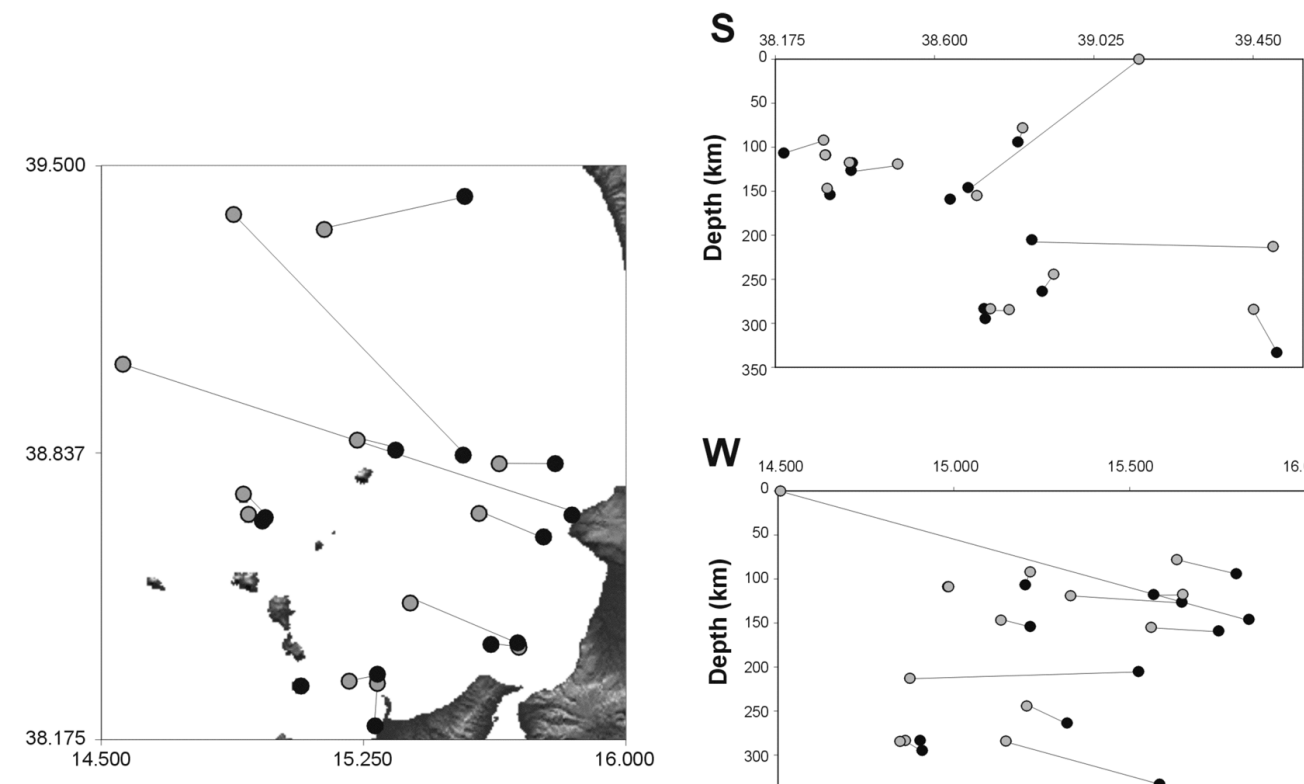

$\mathbf{N}$

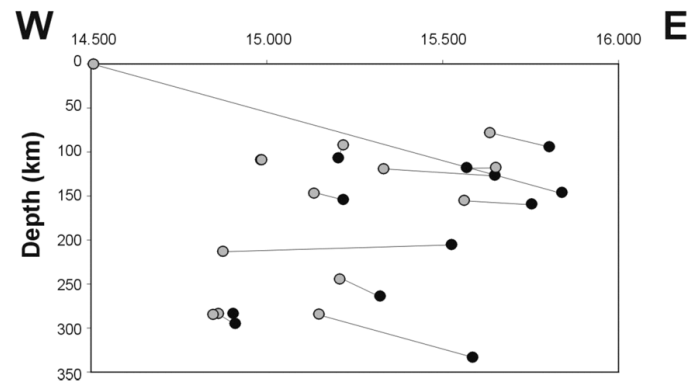

Fig. 4. Cluster 1 - Deep events. Grey circles represent the located events using the land-stations; black circles are the integrated locations. Black lines join the two different locations of the same event. On the right, S-N and W-E sections are presented.
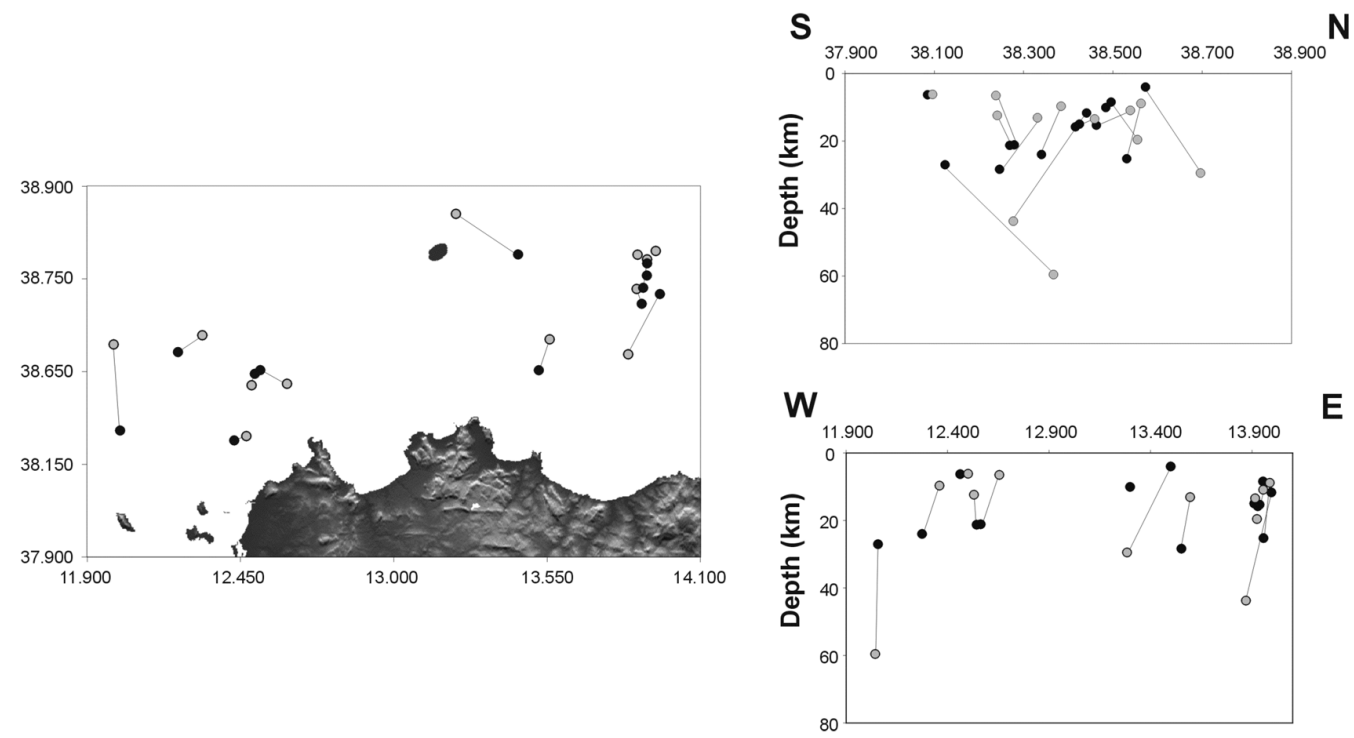

Fig. 5. Cluster 2 - Ustica. Grey circles represent the located events using the land-stations; black circles are the integrated locations. Black lines join the two different locations of the same event. On the right, S-N and W-E sections are presented. 

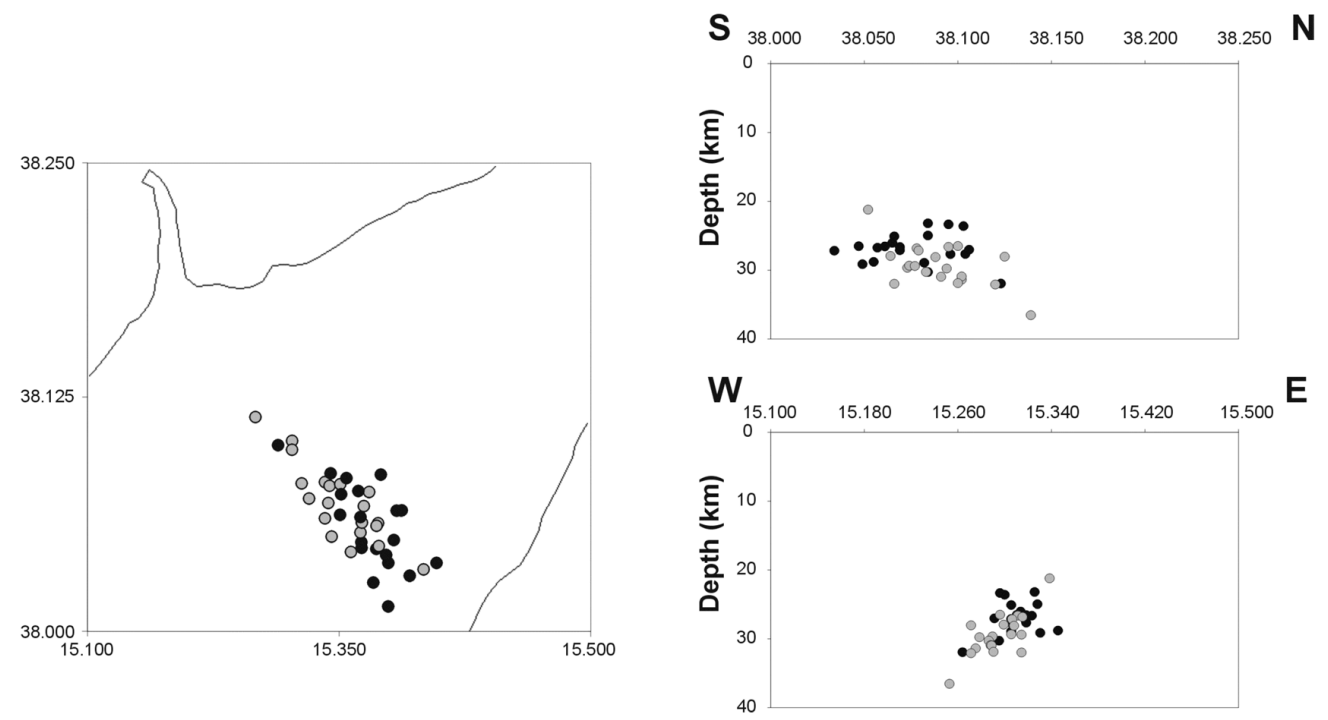

Fig. 6. Cluster 3 - Seismic swarm of the Nebrodi-Peloritani system. Grey circles represent the located events using the land-stations; black circles are the integrated locations. On the right, S-N and W-E sections are presented.

gap. On the other hand the extension of the observation area to the Tyrrhenian Sea by integrating the OBSN increases the complexity of the velocity structure of the underlying crust, such that an unique $1 \mathrm{D}$ velocity model is no more suitable. In this case classical localisation routines, which use a 1D model, do not necessarily improve the quality of the localisations. The choice to apply the HYPOSAT location routine allowed to incorporate an additional local crustal velocity model (fig. 3), depending on the respective analysed epicentral area (cluster).

Only the combined use of both i) a seismic network extended by integration of the OBSN, and ii) the application of an enhanced location routine, that includes different local velocity models, leaded to a significant improvement of the relocation results (table I).

\subsection{Cluster 1: «deep» seismic events in the Southern Tyrrhenian Sea}

Hypocenters occurring in the upper mantle beneath the Southern Tyrrhenian Basin are routinely mislocated by the INGV-network. The unequal distribution of the land-based stations, as well as the quasi-systematic lack of $S$-phases determines poor constraints on the depth of deep events and/or on the origin times.

For the location of such «deep» seismic events, we used the local velocity models described in the Section 4.3. For depths below the Moho all models merge into the upper mantle velocity reported in the model ak135 (Kennett et al., 1995).

The integration of data from the OBSN and the land network data resulted always in a more stable location result in terms of RMS, horizontal and depths errors, while the depth values of the hypocenters remained stable or increased by using the integrated data set.

To solve the problem of a reliable depth of foci, at first we fixed the depth at $100 \mathrm{~km}$ for each deep earthquake. Afterwards, the depth was increased by $20 \mathrm{~km}$ steps and we found the optimum epicentral location at each depth. The final depth of each earthquake is chosen when the solution of the inversion is stable and it represents the solution which minimises the RMS residual error. We then relocated the event using the determined optimal depth. 


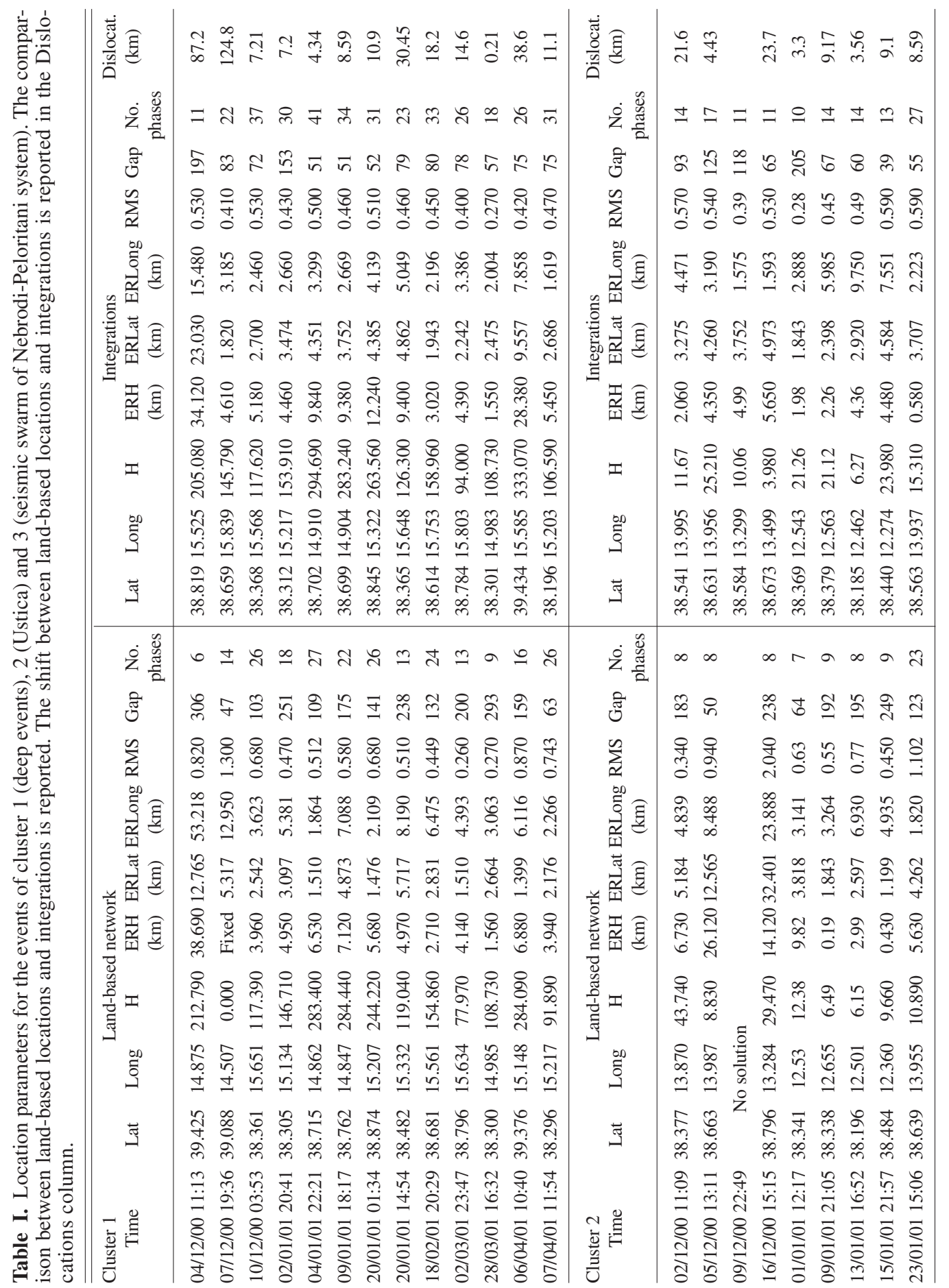




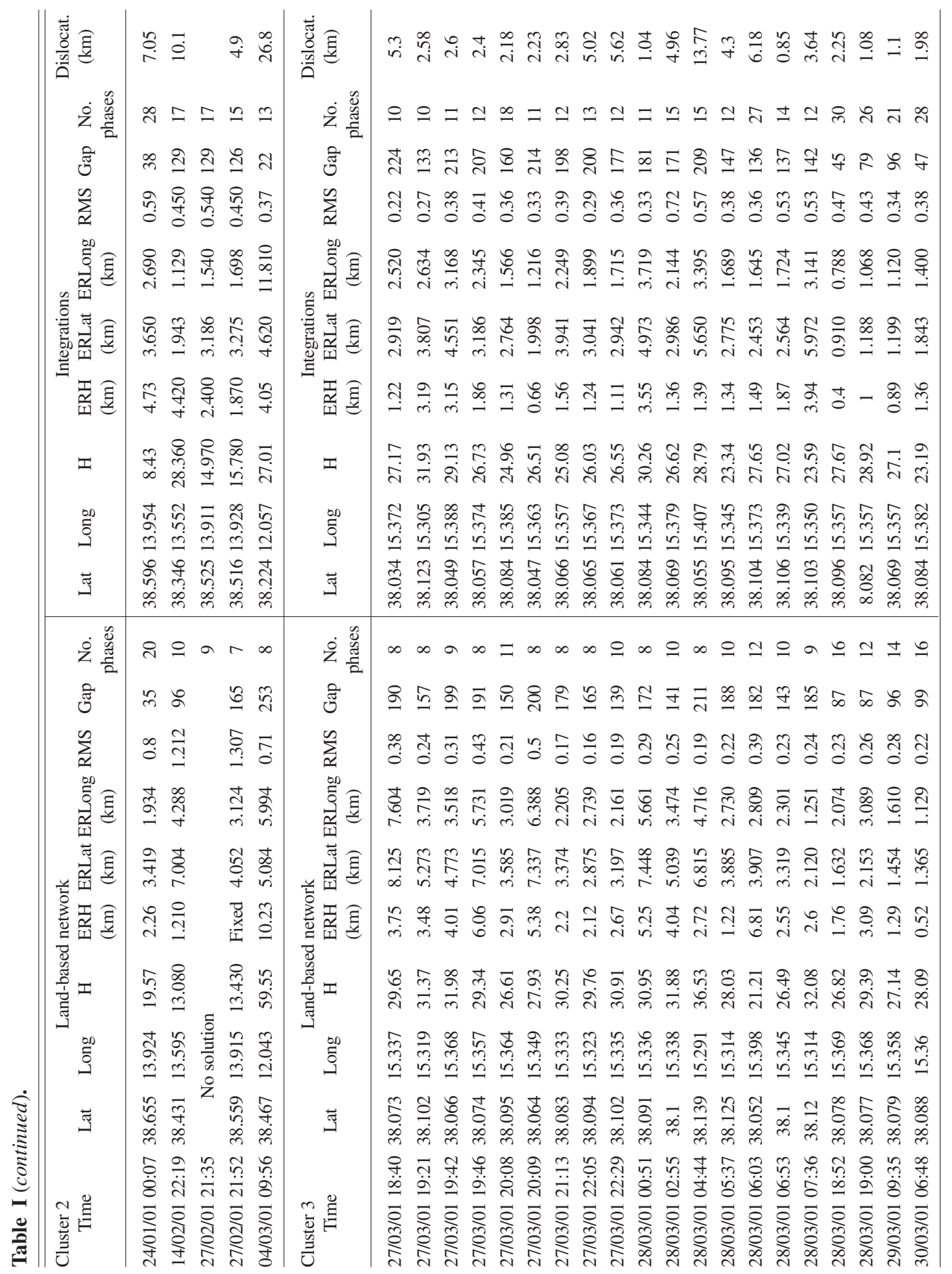


The deepest events occurred in the vicinity of Stromboli, Panarea and Salina islands, according to the scheme of distribution of the foci proposed by Blot (1971), with focal depths ranging between $260 \mathrm{~km}$ and $330 \mathrm{~km}$. As reported in table I (See column relative to the Dislocations) and fig. 4 some of the relocations shifted the original epicentre by even more than $100 \mathrm{~km}$ in the southeastern direction. Moreover, the events recorded in the Tyrrhenian Basin are more dislocated than the events located near the coasts of Calabria and Sicily (fig. 4).

\subsection{Cluster 2: Ustica Island}

Throughout the TYDE experiment, part of the seismic activity occurred off-shore of northwestern Sicily in correspondence of a large area surrounding Ustica Island. We analysed waveforms of 14 earthquakes, occurring between 2000, December 2-2001, March 4. Time readings of RSNC stations have been integrated with readings from OBS. The land-based location and integration of these events showed interesting aspects, mainly regarding the choice of the $1 \mathrm{D}$ velocity model for the location process. Indeed, it was necessary to try different models to locate the events of this cluster and reach a stable solution. This is likely due to the large epicentral area (fig. 5), characterised by different structural sectors. Concerning locations with land-based stations data only, no solutions were admitted for two events of the cluster. On the other hand the integration provided acceptable hypocentral solutions. In general, the integrated time readings, using land and OBSN stations, improved the quality of the events location, with low RMS value, epicentre errors and azimuthal gap (table I). It is noteworthy that hypocenters shifted towards shallower levels confirming the crustal origin of this cluster.

Figure 5 shows the final integrated epicentre locations and the relative N-S and W-E sections of 14 best located events, compared with those obtained from land-based data.

It is important to emphasize, that several tens of small earthquakes were recorded only by the GEOSTAR hydrophone, revealing an intense microseismicity close to the Ustica Island.

\subsection{Cluster 3: NE-Sicily: seismic swarm of Mts. Nebrodi-Peloritani system}

Between 26-30 March, 2001, a small seismic swarm, comprising 53 earthquakes with magnitude $M d<3.0$, occurred in the area of Mts. Nebrodi-Peloritani system (NE of Sicily). Twenty of the most energetic events of the swarm have been analysed, comparing locations i) of the land-based network (grey dots in fig. 6) and ii) of the integrated network using the nearest OBS-OBH (black dots in fig. 6).

The addition of a few time readings from OBS stations significantly improved the locations in terms of hypocentral errors (table I), while the computed value of gap and RMS became slightly higher than for the land-based locations. N-S and W-E sections of the analysed seismic swarm, depict a well confined seismogenic layer in the lower crust, at mean depth of about $27 \mathrm{~km}$.

As expected, small differences in hypocenter locations (up to $2 \mathrm{~km}$ in focal depth and 6 $\mathrm{km}$ in epicentre) are observed when locating the on-shore events with and without OBS-OBH data, with respect to clusters of seismicity previously shown.

\section{Locations of not reported earthquakes}

\subsection{Integrated locations from OBSN with single station triggers from RSNC}

Some weak seismic events occurred inside the Tyrrhenian Basin and in the coastal areas, have been recorded only by a one or two stations of the land-based INGV-network, not allowing an hypocentral determination. We extracted the OBSN waveforms of 31 single-station triggers reported by INGV bulletin and performed the locations of the integrated data set (table II).

The epicentral distribution of this cluster has been reported in fig. 7. According to the quality of the locations we defined three quality factors: A number of arrivals $\geq 8, \mathrm{RMS} \leq 0.7 \mathrm{~s} ; \mathrm{B}$ - number of arrivals $\geq 6,0.7 \leq \mathrm{RMS} \leq 1.2 \mathrm{~s} ; \mathrm{C}-$ number of arrivals $\leq 6, \mathrm{RMS}<1.2 \mathrm{~s}$ ). Based on this assumption, the locations of 19 earthquakes are of quality A, 10 locations have quality factor B, while only 2 locations have quality factor $\mathrm{C}$. 
Table II. Locations parameters for categories «integrated locations of new events» and «weak local events».

\begin{tabular}{|c|c|c|c|c|c|c|c|c|c|}
\hline \multicolumn{10}{|c|}{ Integrated locations of new events } \\
\hline Time & Lat & Long & $\mathrm{H}$ & $\mathrm{ERH}(\mathrm{km})$ & ERLat $(\mathrm{km})$ & ERLong (km) & RMS & Gap & No. phases \\
\hline 07/12/00 02:11 & 38.37 & 15.479 & 115.56 & 7.13 & 5.395 & 4.830 & 0.47 & 120 & 23 \\
\hline 09/12/00 08:11 & 38.773 & 15.956 & 49.22 & 26.09 & 14.708 & 21.026 & 1 & 261 & 15 \\
\hline 09/12/00 19:50 & 38.774 & 13.297 & 15.16 & 1 & 61.949 & 15.601 & 0.67 & 91 & 9 \\
\hline 12/12/00 03:27 & 38.288 & 13.919 & 0 & 1 & 3.286 & 15.418 & 0.81 & 219 & 9 \\
\hline 12/12/00 11:04 & 38.192 & 14.77 & 114.84 & 15.74 & 13.009 & 7.446 & 0.47 & 140 & 11 \\
\hline 12/12/00 17:09 & 38.259 & 14.309 & 9.31 & 1.04 & 4.052 & 3.281 & 1.01 & 145 & 12 \\
\hline 29/12/00 09:35 & 38.698 & 13.904 & 10 & 1 & 8.725 & 13.563 & 1.35 & 88 & 13 \\
\hline 07/01/01 22:51 & 38.417 & 15.821 & 37.73 & 5.95 & 3.152 & 3.159 & 0.69 & 102 & 25 \\
\hline 08/01/01 03:12 & 38.378 & 13.092 & 33.17 & 1 & 15.784 & 13.816 & 1.02 & 57 & 11 \\
\hline 10/01/01 11:43 & 37.999 & 15.149 & 14.32 & 12.97 & 14.752 & 9.835 & 1.06 & 203 & 13 \\
\hline 22/01/01 07:42 & 37.91 & 14.083 & 6.96 & 7.02 & 12.232 & 11.253 & 0.68 & 174 & 1 \\
\hline 28/01/01 02:02 & 38.345 & 14.641 & 21.68 & 2.67 & 5.128 & 2.345 & 0.7 & 218 & 16 \\
\hline 14/02/01 15:34 & 37.736 & 14.246 & 7.08 & 4.98 & 9.579 & 3.194 & 0.58 & 265 & 12 \\
\hline 21/02/01 05:12 & 38.523 & 14.823 & 10.93 & 7.33 & 4.052 & 2.048 & 0.92 & 155 & 12 \\
\hline 22/02/01 00:49 & 38.473 & 14.828 & 16.18 & 3.32 & 9.735 & 4.524 & 0.69 & 222 & 9 \\
\hline 24/02/01 11:32 & 38.199 & 15.217 & 107.94 & 9.81 & 8.103 & 4.078 & 0.38 & 186 & 17 \\
\hline 09/03/01 05:48 & 39.543 & 14.018 & 49.25 & 79.57 & 23.477 & 22.409 & 0.76 & 271 & 8 \\
\hline 18/03/01 06:59 & 38.51 & 15.335 & 189.46 & 3.92 & 3.985 & 3.159 & 0.46 & 76 & 36 \\
\hline 19/03/01 04:59 & 37.719 & 15.763 & 1.75 & 4.9 & 6.161 & 4.025 & 0.13 & 278 & 10 \\
\hline 19/03/01 13:44 & 37.889 & 14.009 & 0.1 & 5.28 & 6.971 & 9.310 & 0.82 & 277 & 17 \\
\hline 21/03/01 15:30 & 38.414 & 15.527 & 118.61 & 1.51 & 2.797 & 2.406 & 0.32 & 116 & 25 \\
\hline 24/03/01 17:38 & 38.038 & 14.504 & 12.37 & 0.43 & 3.164 & 2.039 & 0.29 & 129 & 13 \\
\hline 24/03/01 22:02 & 38.669 & 12.61 & 25.53 & 5.7 & 3.985 & 7.831 & 0.21 & 289 & 10 \\
\hline 25/03/01 12:51 & 39.987 & 16.096 & 6.9 & 0.65 & 3.707 & 2.879 & 1.23 & 69 & 32 \\
\hline 26/03/01 03:07 & 38.124 & 14.418 & 13.64 & 1 & 9.335 & 9.931 & 0.54 & 174 & 12 \\
\hline 28/03/01 02:08 & 38.313 & 15.526 & 54.54 & 19.52 & 11.477 & 11.891 & 0.82 & 159 & 14 \\
\hline 29/03/01 00:25 & 38.25 & 15.055 & 9.32 & 1 & 34.321 & 14.945 & 0.91 & 260 & 6 \\
\hline 29/03/01 05:51 & 38.052 & 14.513 & 12.9 & 4.75 & 2.875 & 2.126 & 0.36 & 123 & 14 \\
\hline 31/03/01 19:39 & 38.028 & 14.524 & 11.44 & 1 & 4.318 & 3.255 & 0.43 & 131 & 15 \\
\hline 12/04/01 21:55 & 38.272 & 14.196 & 22.49 & 2.85 & 3.386 & 3.964 & 0.66 & 125 & 17 \\
\hline 17/04/01 03:34 & 38.079 & 15.185 & 19.56 & 0.93 & 2.431 & 1.251 & 0.65 & 230 & 15 \\
\hline \multicolumn{10}{|c|}{ Weak local events } \\
\hline Time & Lat & Long & $\mathrm{H}$ & ERH $(\mathrm{km})$ & ERLat $(\mathrm{km})$ & ERLong (km) & RMS & Gap & No. phas \\
\hline 07/12/00 09:39 & 38.519 & 14.768 & 20.01 & 1.13 & 3.1 & 1.706 & 0.36 & 226 & 11 \\
\hline 11/12/00 01:45 & 38.515 & 13.99 & 2.37 & 0.66 & 1.243 & 2.293 & 0.19 & 294 & 9 \\
\hline 21/12/00 03:29 & 38.574 & 14.465 & 0.1 & 7.36 & 1.499 & 1.033 & 1.13 & 115 & 8 \\
\hline 26/12/00 15:34 & 38.238 & 15.188 & 44.95 & 9.7 & 12.632 & 5.163 & 0.58 & 276 & 9 \\
\hline 03/01/01 07:27 & 38.44 & 13.862 & 5.44 & 11.8 & 28.716 & 19.049 & 0.66 & 322 & 6 \\
\hline 05/01/01 08:21 & 38.499 & 15.156 & 13.56 & Fixed & 13.553 & 11.506 & 2.92 & 121 & 9 \\
\hline 11/01/01 20:40 & 38.46 & 14.076 & 9.59 & Fixed & 11.056 & 9.923 & 2.05 & 226 & 8 \\
\hline 12/01/01 11:49 & 38.524 & 14.573 & 15.6 & 3.56 & 2.609 & 3.623 & 0.53 & 149 & 10 \\
\hline 26/01/01 17:10 & 38.542 & 14.205 & 14.58 & 4.65 & 3.230 & 3.063 & 0.6 & 123 & 14 \\
\hline 27/01/01 12:54 & 38.521 & 14.036 & 6.49 & Fixed & 4.784 & 3.561 & 0.84 & 218 & 12 \\
\hline 06/02/01 11:49 & 38.504 & 13.86 & 14.38 & 0.08 & 0.833 & 2.065 & 0.34 & 319 & 6 \\
\hline 06/02/01 17:14 & 38.754 & 15.868 & 39.72 & 11.01 & 2.076 & 6.545 & 0.27 & 26 & 14 \\
\hline 07/02/01 15:36 & 38.205 & 15.72 & 68.07 & 13.55 & 12.876 & 14.971 & 0.54 & 316 & 10 \\
\hline 12/02/01 05:44 & 38.469 & 14.543 & 18.82 & 3.62 & 1.621 & 1.234 & 0.25 & 257 & 7 \\
\hline 17/02/01 21:14 & 38.468 & 13.891 & 3.06 & 8.68 & 5.672 & 13.423 & 0.58 & 318 & 8 \\
\hline
\end{tabular}


Table II (continued).

\begin{tabular}{|c|c|c|c|c|c|c|c|c|c|}
\hline & & & & Weak loc & 1 events & & & & \\
\hline Time & Lat & Long & $\mathrm{H}$ & ERH $(\mathrm{km})$ & ERLat (km) & ERLong (km) & RMS & Gap & No. phases \\
\hline 21/02/01 04:27 & 38.465 & 14.822 & 23.44 & 3.06 & 3.041 & 2.205 & 0.43 & 175 & 16 \\
\hline 03/03/01 03:07 & 38.437 & 14.407 & 12.95 & 3.15 & 8.236 & 3.561 & 0.48 & 194 & 13 \\
\hline 07/03/01 17:24 & 37.934 & 14.861 & 34.78 & 52.62 & 21.534 & 5.311 & 0.23 & 284 & 9 \\
\hline 10/03/01 11:46 & 38.203 & 15.073 & 11.49 & 4.51 & 11.411 & 4.725 & 0.58 & 272 & 9 \\
\hline 12/03/01 23:18 & 38.63 & 14.924 & 27.17 & 1.26 & 4.706 & 2.100 & 0.47 & 237 & 8 \\
\hline 14/03/01 06:02 & 38.549 & 15.258 & 20.27 & 3.06 & 5.461 & 11.568 & 0.81 & 186 & 7 \\
\hline 16/03/01 09:44 & 38.275 & 13.416 & 41.57 & 1 & 35.109 & 5.311 & 0.91 & 222 & 7 \\
\hline 24/03/01 22:44 & 38.448 & 14.572 & 14.52 & 0.23 & 0.211 & 0.175 & 0.03 & 50 & 7 \\
\hline 26/03/01 17:18 & 38.206 & 15.402 & 63.43 & 17.87 & 17.505 & 14.753 & 1 & 297 & 13 \\
\hline 28/03/01 04:02 & 38.203 & 14.946 & 34.87 & 9.49 & 5.350 & 2.546 & 0.45 & 259 & 12 \\
\hline 28/03/01 05:57 & 38.293 & 14.937 & 36.01 & 0.82 & 15.951 & 6.781 & 1 & 236 & 9 \\
\hline 28/03/01 18:09 & 39.227 & 13.918 & 30.77 & Fixed & 50.605 & 34.781 & 1.54 & 305 & 8 \\
\hline 29/03/01 00:23 & 38.318 & 15.213 & 29.08 & Fixed & 33.999 & 6.493 & 1.25 & 286 & 8 \\
\hline 01/04/01 08:02 & 38.326 & 13.787 & 20.62 & Fixed & 139.638 & 195.729 & 2.13 & 331 & 6 \\
\hline 03/04/01 17:50 & 38.502 & 14.18 & 0 & Fixed & 13.775 & 9.205 & 1.35 & 289 & 6 \\
\hline 09/04/01 02:29 & 38.365 & 14.235 & 1.16 & 1.57 & 3.130 & 0.788 & 0.27 & 264 & 6 \\
\hline $10 / 04 / 01 \quad 14: 56$ & 39.063 & 15.537 & 34.35 & 14.08 & 6.649 & 20.195 & 0.91 & 32 & 10 \\
\hline 12/04/01 10:23 & 38.573 & 14.531 & 18.33 & Fixed & 1.410 & 1.934 & 0.63 & 215 & 7 \\
\hline 15/04/01 21:54 & 38.135 & 15.175 & 11.33 & Fixed & 7.326 & 5.539 & 0.93 & 285 & 11 \\
\hline 18/04/01 10:01 & 38.577 & 14.074 & 0 & Fixed & 2.331 & 1.295 & 1.26 & 207 & 7 \\
\hline 18/04/01 16:00 & 38.553 & 14.458 & 25.53 & Fixed & 3.896 & 5.040 & 0.99 & 157 & 11 \\
\hline 18/04/01 16:03 & 38.503 & 14.438 & 16.7 & 2.95 & 1.454 & 0.665 & 0.1 & 204 & 7 \\
\hline
\end{tabular}
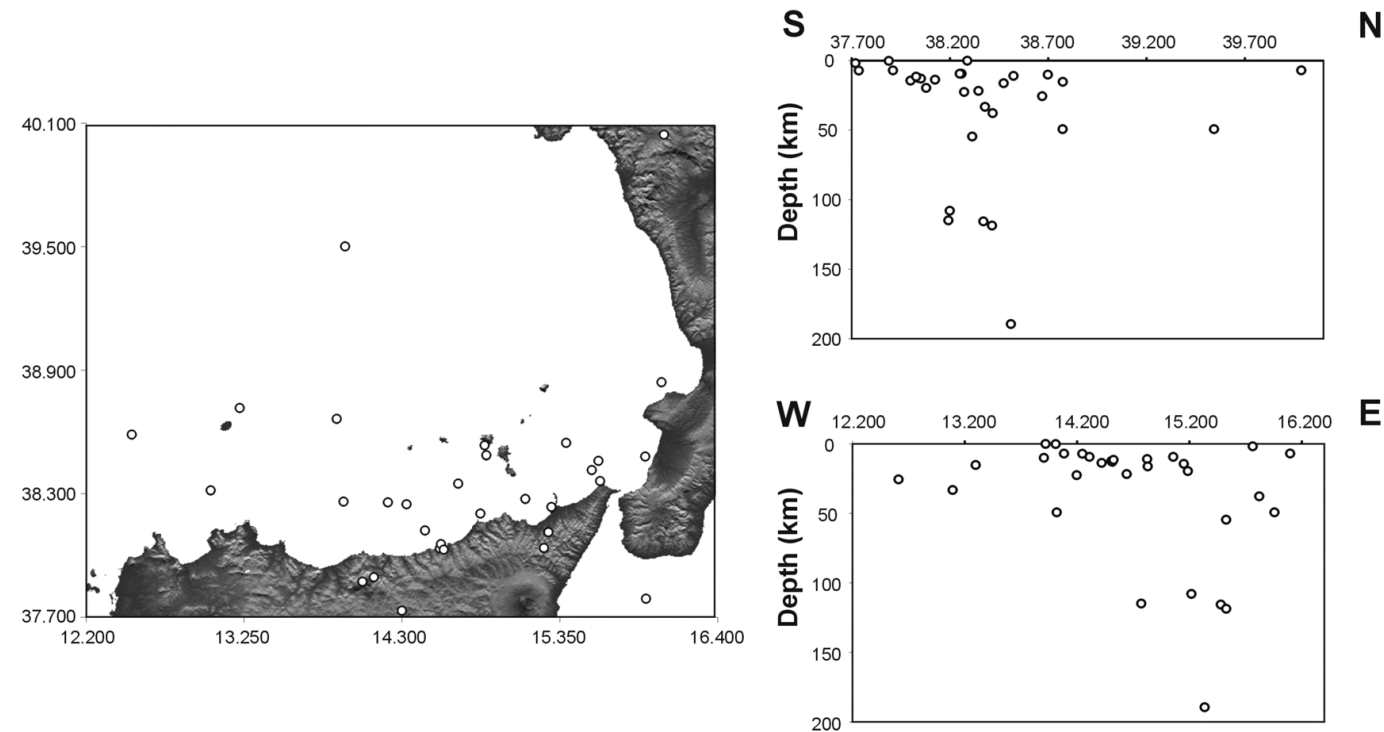

Fig. 7. Integrated locations of new events. Locations of the events and S-N and W-E sections are presented on left and right sides, respectively. 

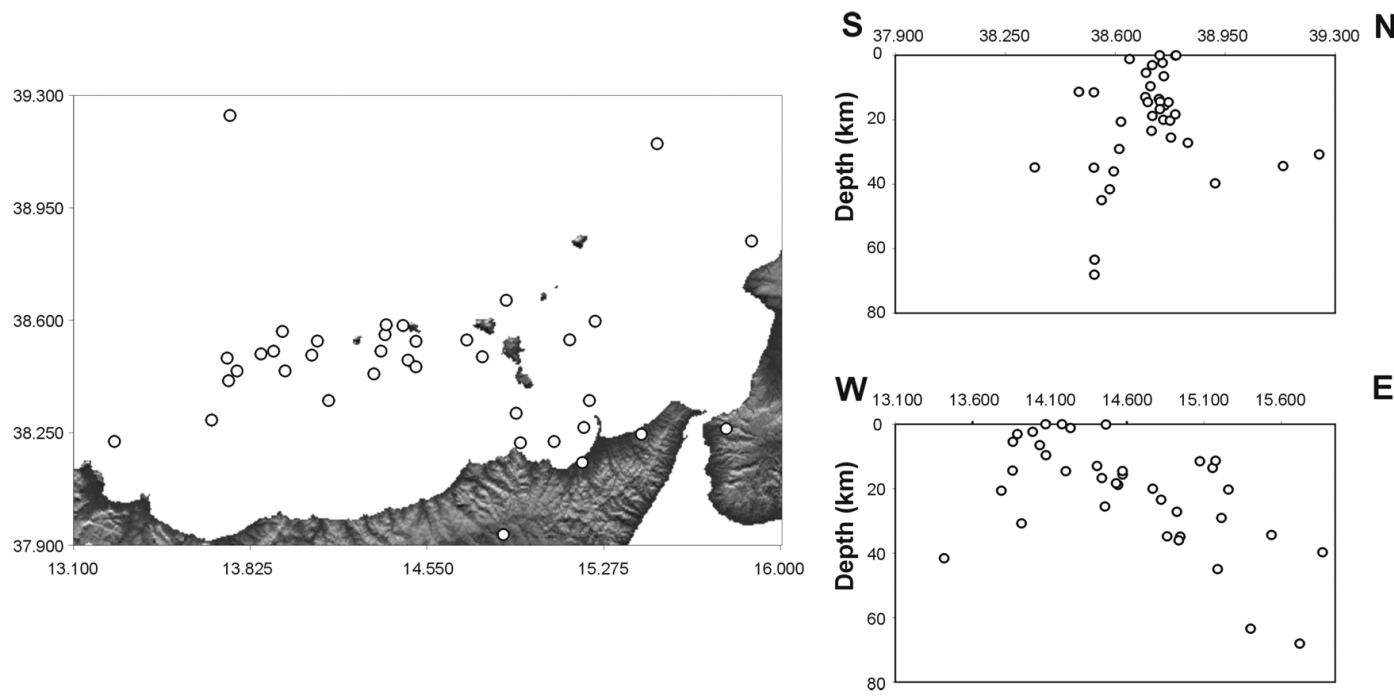

Fig. 8. Weak local events. Locations of the events and S-N and W-E sections are presented on left and right sides, respectively.

\subsection{Weak local events recorded by the OBSN}

During the 6-months experiment about 400 low magnitude local events have been detected only by the OBSN, with a sufficient number of time arrivals to permit a location. The surprisingly high number of earthquakes recorded only by the OBSN emphasizes that seismic activity within the crust in the Tyrrhenian Sea is systematically underestimated by land networks.

The observed waveforms suggest the occurrence both of volcanic and tectonic earthquakes. Micro-earthquakes have been roughly located by examining the succession of arrival times at the OBSN stations and by the distribution of $S$ $P$ times. The recorded micro-seismicity at the OBS05 and OBS06 stations seem to be associable to very local shocks $(S-P \leq 3$ s), probably linked to the volcanic activity of the Stromboli area (Dahm et al., 2002). On the western sector of the study area, a large number of small earthquakes were recorded only from the GEOSTAR hydrophone.

Location has been successful for some events with at least three $P$ - and one $S$-phases.
The distribution and parameters of 37 earthquakes are presented in fig. 8 and table II, respectively. The seismic events have been observed mainly in the western part of the Aeolian Volcanic Arc. The located micro-earthquakes have depth values down to around $70 \mathrm{~km}$.

\section{Conclusions}

Many low magnitude earthquakes occur along the tectonic and volcanic structures of the Southern Tyrrhenian Sea, but location of earthquakes recorded by the conventional land network continue to be less than satisfactory.

The use of data recorded from a 6-months OBSN, jointly with the recording from land networks, produced an evident improvement in the location of the seismicity that occurred in the Southern Tyrrhenian Basin. The integrated network of OBS-OBH and land stations recorded about 800 local events, while about 400 weak local events have been detected by the OBSN only.

The comparison between the locations obtained from the use of land networks only, and 
the ones obtained by integrations of on/offshore networks shows strong differences in the epicentre distributions. Differences are more pronounced when the events occurred in correspondence of the basin of Tyrrhenian Sea, and less pronounced when the events occurred near the coastal area of Sicily and Calabria, where the coverage of on-land stations is better (fig. 4). Besides, the integrated locations are greatly improved in terms of RMS residuals, azimuthal gap, and epicentral and hypocentral errors (table I).

From the joint RSNC and INGV-CT database, we selected some events relative to three spatial clusters of seismicity which are representative of the whole seismic activity of the area. The improvement of the depth estimation of deep events (cluster 1) allowed to better clarify their correlation with the Wadati-Benioff zone, which characterises the Southern Tyrrhenian Sea in Calabria and north-eastern Sicily sectors. The second cluster comprises some crustal earthquakes located in the north-western Sicily off-shore: this activity can be correlated with the submerged sector of the ApenninicMaghrebide Chain confining with the oceanic crust of the Tyrrhenian Basin. After the integration we were able to assign some crustal earthquakes to the deep cluster, and vice versa. The analysis of the on-shore seismic swarm of cluster 3 (in the Nebrodi-Peloritani area) led to an improvement of locations in terms of depth and epicentral errors.

A noteworthy result of our study is the localisation of 68 new events, not previously reported in the bulletin. The association of the single stations triggers from RSNC integrated with the OBS-OBH readings, allowed for the location of 31 low magnitude events mainly in the coastal region, where the geometry of the on-shore networks prevents the location of this seismicity. Among these new events, five of them are part of the deep events cluster and three of the Ustica cluster. In addition to the integrated locations of new events, we analysed a cluster of 37 weak local events recorded only by OBSN. Most of these events occurred in the western sector of the Aeolian volcanic arc, while a few of them took place in the coastal area of Northern Sicily.
Concerning the depth of the located events, most of them present a crustal origin, some earthquakes occurred in the upper mantle in the 30-100 km depth range, while the deeper ones have focus around $300 \mathrm{~km}$. The distribution of not reported hypocenters (see E-W sections of figs. 7 and 8) put in evidence that the more eastern events lie on the Wadati-Benioff plane, while a crustal seismicity occurs in the western sector of Tyrrhenian Basin. The position of intermediate-deep earthquakes (between the Benioff plane and the crust) could be related to active processes in the mantle.

Taking into account the presence of volcanic structures within the study area, some local shocks can be associated to the volcanic seamounts in the south-eastern part of the Tyrrhenian Sea.

The OBSs tectonic micro-earthquakes recorded both in the mantle and crust beneath the Tyrrhenian Sea, together with volcanic shocks, may be considered the demonstration of the lively structural frame encompassing the Aeolian Archipelago.

\section{Acknowledgements}

The authors are grateful to Christian Mueller and one anonymous referee for their useful review. Many thanks are due to Laura Beranzoli, Paolo Favali, and Ernst Flueh for conceiving the TYDE project. We appreciated the excellent work of Jörg Reinhard, André Polster, Andreas Wittwer, Martin Thorwart, and Rolf Herber during the survey in the Tyrrhenian Sea and the data management at the Hamburg Institute of Geophysics. Masters and crew of the $\mathrm{R} / \mathrm{V}$ Urania and Thetis provided fundamental help during the realisation of OBS surveys in the Southern Tyrrhenian Sea.

\section{REFERENCES}

AA.VV. (1991): Structural model of Italy and gravity map (1:500000), Quad. Ric. Sci, 114/3, PFG-CNR, Florence.

ANDERSON, D.L. and J. JACKSON (1987): The deep seismicity of the Tyrrhenian Sea, Geophys. J. R. Astron. Soc., 91, 613-637.

Aoyagi, Y., T. Murayama, M. Shinohara, K. Suyehiro, L. 
Beranzoli, G. Etiope, P. Favali, F. Frugoni and G. SMriglio (1997): Microseismicity around Tyrrhenian Sea as revealed by ocean bottom seismographic observation, in Abstracts of the 29th General Assembly of International Association of Seismology and Physics of Earth Interior, p. 215.

ARgNANI, A. (2000): The Southern Tyrrhenian subduction system: recent evolution and neotectonic implications, Ann. Geofis., 43 (3), 585-607.

Barberi, F., F. Innocenti, G. Ferrara, J. Keller and L. VILLARI (1974): Evolution of the Aeolian Arc volcanism (Southern Tyrrhenian Sea), Earth Planet. Sci. Lett., 21, 269-276.

Bebel, D.J., P.R. Stoddard and M.T. Woods (1992): A comparison of epicenter relocation techniques: a case study for the Juan de Fuca plate, Phys. Earth Planet. Inter., 75, 25-38.

Beranzoli, L., Y. Aoyagi, T. Braun, M. Calcara, G. Etiope, P. Favali, F. Frugoni, T. Murayama, M. ShiNOHARA, G. SMriglio and K. SuYeHIRO (1999): Microseismicity of the tyrrhenian basin monitored by an «Ocean Bottom Seismometer Network», in Proceedings of the 17th Convegno del Gruppo Nazionale di Geofisica della Terra Solida, 10-12 November 1998, Roma (Italy), Appendice Atti 1997, Session No. 08, Contrib. n.19, 2 pp. (on CD-ROM).

Beranzoli, L., T. Braun, M. Calcara, D. Calore, R. Campaci, J.-M. Coudeville, A. De Santis, D. Di Mauro, G. Etiope, P. Favali, F. Frugoni, J.-L. Fuda, F. Gamberi, F. Gasparoni, H.W. Gerber, M. Marani, J. Marvaldi, C. Millot, C. Montuori, P. Palangio, G. Romeo and G. SMrigLio (2000): European seafloor observatory offers new possibilities for deep-sea study, Eos, Trans. Am. Geophys. Un., 81 (5), 45-49.

Blot, C. (1971): Etudes sismologiques de Vulcano, Cah. Orstom, Ser. Geophys., 11, pp. 32.

Braun, T., T. Dahm, E. Flüh, M. Thorwart, R.M. AzZara, L. Beranzoli, G. D’Anna, P. Favali, F. Frugoni, S. Mazza, C. Montuori and G. Smriglio (2001): Report of a joint german-italian seismological project in the Southern Tyrrhenian Sea, in Abstracts of 20th Convegno del Gruppo Nazionale di Geofisica della Terra Solida, 6-8 November 2001, Roma (Italy), 37-38.

Carapezza, E., M. T. Carrozzo, P. Colella, P. Cosentino, R. De Domenico, P. Fradella, E. Gagliano CanDela, D. Luzio, C. MargotTa and T. Quarta (1987): Interpretazione comparata sismica e gravimetrica lungo il profilo crostale Capo Milazzo-Geraci (Sicilia), in Proceedings of the 6th Convegno Annuale del Gruppo Nazionale di Geofisica della Terra Solida, Roma, vol. 3, 1115-1123.

Chironi, C., L. De Luca, I. Guerra, D. Luzio, A. MoretTI, M. VitAle and SEALAND Group (2000): Crustal stuctures of the Tyrrhenian Sea and Sicily Channel on the basis of the $M 25, M 26, M 28, M 39$ WARR profiles, Boll. Soc. Geol. Ital., 119, 189-203.

Cimini, G B. (1999): $P$-wave deep velocity structure of the Southern Tyrrhenian subduction zone from nonlinear telesismic travel time tomography, Geophys. Res. Lett., 26, 3709-3712.

Dahm, T., M. Thorwart, E. R. Flueh, T. Braun, R. HerBer, P. Favali, L. Beranzoli, G. D'Anna, F. Frugoni and G. Smriglio (2002): First deployment of new ocean bottom broadband seismological instruments in the Tyrrhenian Sea reveals unknown centers of submarine activity, Eos, Trans. Am. Gophys. Un., 83 (29), 309-320.

Del Pezzo E., R. Maresca, M. Martini and R. Scarpa (1984): Seismicity of the Aeolian Islands, Southern Italy, Ann. Geophysicae, 2 (2), 173-180.

Dewey, J.F., M.L. Helman, E. TurCo, D.H.W. Hutton and S.D. KNOTT (1989): Kinematics of the Western Mediterranean, in Alpine Tectonics, edited by M.P. CowARD, D. Dietrich and G. Park, Geol. Soc. London Spec. Publ., 45, 265-283.

Duschenes, J., M.C. Sinha and K.E. Louden (1986): A seismic refraction experiment in the Tyrrhenian Sea, Geophys. J. R. Astron. Soc., 85, 139-160.

Faccenna, C., M. Mattei, R. Funiciello and L. Jolivet (1997): Styles of back arc extension in the Central Mediterranean, Terra Nova, 9, 126-130.

FinetTi, I., and A. Del Ben (1986): Geophysical study of the Tyrrhenian opening, Boll. Geofis. Teor. Appl., XXVIII (110), 75-152.

Frazzetta, G., G. LanZafame and L. Villari (1982): Deformazioni e tettonica attiva a Lipari e Vulcano (Eolie), Mem. Soc. Geol. Ital., 24, 293-297.

Gasparoni, F., P Favali and G. Smriglio (2002): GEOSTAR seafloor observatory successfully completes first deep-sea mission, in Oceanology International 2002 Conference Proceedings (on CD-ROM).

GhisetTi, F. and L. VeZZANi (1982): Different styles of deformation in the Calabrian Arc (Southern Italy): implications for a seismotectonic zoning, Tectonophysics, 85, 149-165.

Giardini, D. and M. VelonÀ (1991): The deep seismicity of the Tyrrhenian Sea, Terra Nova, 3, 57-64.

Hino, R., T. Kanazawa and A. Hasegawa (1996): Interplate seismic activity near the Northern Japan Trench deduced from ocean bottom and land-based seismic observations, Phys. Earth Planet. Inter., 93, 37-52.

Hirn, A., A. Nercessian, M. Sapin, F. Ferrucci and G. WitTLINGER (1991): Seismic heterogeneity of Mt. Etna: structure and activity, Geophys. J. Int., 105, 139-153.

Husen, S., E. Kissling and E.R. FlueH (2000): Local earthquakes tomography of shallow subduction in North Chile: a combined on-shore and off-shore study, $J$. Geophys. Res., 105 (B12), 28183-28198.

INGV (2003): Italian Seismic Catalogue from 1450 B.C. to 2003 (Roma).

KASTENS, K. and J. MASCLE (1990): The geological evolution of the Tyrrhenian Sea: an introduction to the scientific results of ODP Leg 107, Proceedings of the ODP, Sci. Res., 107 (College Station TX, Ocean Drilling Program), 3-26.

Kennett, B.L.N., E.R. Engdahl and R. Buland (1995): Constraints on seismic velocities in the Earth from travel-times, Geophys. J. Int., 122, 108-124.

Lawton, J., C. Frohlich, H. Pulpan and G.V. Latham (1982): Earthquake activity at the Kodiak continental shelf, Alaska, determined by land and ocean bottom seismograph networks, Bull. Seismol. Soc. Am., 72, 207-220.

LEE, W.H. and J.C. LAHR (1972): HYPO71: a computer program for determining, hypocenter, magnitude and first motion pattern of local earthquakes, US Geol. Surv. Open-File Rep., p. 100. 
MALinVERnO, A. and W.B.F. RYAn (1986): Extension in the Tyrrhenian Sea and shortening in the Apennines as result of arc migration driver by sinking of the lithosphere, Tectonics, 5, 227-245.

MARANi, M.P. and T. TRUA (2002): Thermal constriction and slab tearing at the origin of a superinflated spreading ridge: Marsili volcano (Tyrrhenian Sea), J. Geophys. Res., 107 (B9), 2188-2202.

Meletti, C., E. Patacca and P. Scandone (2000): Construction of a seismotectonic model: the case of Italy, Pure Appl. Geophys., 157, 11-35.

Neri, G., D. Caccamo, O. Cocina and A. Montalto (1996): Geodynamic implications of earthquake data in the Southern Tyrrhenian Sea, Tectonophysics, 258, 233-249.

Pepe, F., G. Bertotti, F. Cella and E. Marsella (1999): Rifted margin formation in the South Tyrrhenian Sea: a high-resolution seismic profile across the North Sicily passive continental margin, Tectonics, 19 (2), 241-257.

Piromallo, C. and A. Morelli (1997): Imaging the Medi- terranean upper mantle by $P$-wave travel time tomography, Ann. Geofis., XL (4), 963-979.

RecQ, M., J.P. Rehault, L. Steinmetz and A. Fabbri (1984): Amincissement de la croûte et accrétion au centre du bassin Tyrrhénien d'après la sismique réfraction, Mar. Geol., 55, 411-428.

SCHWEITZER, J. (2001): HYPOSAT - An enhanced routine to locate seismic events, Pure Appl. Geophys., 158, 277-289.

Selvaggi, G. and C. Chiarabba (1995): Seismicity and $P$ wave image of the Southern Tyrrhenian subduction zone, Geophys. J. Int., 121, 818-826.

Soloviev, S.L., I.P. Kuzin, S.A. Kovachev, M. Ferri, I. GuERRA and G. LuONGo (1990): Microearthquakes in the Tyrrhenian Sea as revealed by joint land and seabottom seismographs, Mar. Geol., 94, 131-146.

Steinmetz, L., F. Ferrucci, A. Hirn, C. Morelli and R. NiCOLICH (1983): A $550 \mathrm{~km}$ long moho traverse in Tyrrhenian Sea from OBS recorded $P n$ waves, Geophys. Res. Lett., 10 (6), 428-431. 